(a) The colour (orange) is due to pigment in the skin, and not to the red colour of the nervous system; I may mention that Duges' species, "Prostoma clepsinoides," was yellow ochre, and "Pr. lumbricoideum" was yellow marbled with red; whilst Leidy's "Emea rubra" was yellowish flesh-coloured (probably due to the hæmoglobin in the nervous system).

(b) The anterior pair of eye-spots is further from the prostomium than in Silliman's drawing; I found no third pair of eye-spots, which, however, it is stated, is absent in the young.

(c) The ciliated pits are further forward, being midway between the brain and the anterior end of the body.

(d) The proboscis and its retractor muscle are much more undulating, when withdrawn into the body, than Silliman shows.

The proboscidial spine, with its groups of accessory spines, agrees very closely with the figures given by Silliman.

I can say nothing about the generative organs. For the present, then, I must leave undecided the specific name of this British Tetrastemma.

Anatomical Department, Museum, Oxford, Oct. 12.

\section{Protective Mimicry.}

Mr. Bateson's letter on "Aggressive Mimicry" (NATURE, October 20 ) recalls to my mind a curious case of protective mimicry which came under my notice last August on Dartmoor. Large patches of the heath had been burnt, a common practice on the moorlands to ensure a fresh young growth for the sheep. The whole ground was alive with a common species of orthoptera (Locustina), the small green grasshopper with short antennæ. They leapt aside at every step in the short grass and scrubby heath; upon the burnt patches they were equally numerous, but with this difference--all, without exception, were coal black on abdomen, thorax, and head, whilst the wings were of an ashen hue. So much did the colour adaptation resemble the blackened turf and heath they hopped amongst it was almost impossible to follow them with the eye ; we made many amusing attempts, but were nearly always defeated. I measured one of these burnt patches, and found it to be from thirty to forty yards square. A yard or two from this, on the untouched herbage all the Locustina were bright green. I found one specimen on the borderland in a transition state, not dull all over as I had expected, but in spots and patches of bright green and black. One enemy at least of these insects abounded on the moor, namely, the common lizard (Zootaa vivipara), for I have observed there is no food lizards will eat more greedily than grasshoppers. I have seen some that I have in captivity swallow twenty or thirty in two or three minutes, even after their usual meal of worms. They always beeame greatly excited, if one may apply so warm an expression to such cold-blooded animals, and rushed about the case when a collection of live grasshoppers were thrown to them. Certainly I was much struck by the rapid action of the power possessed by these Locustina on Dartmoor of assimilation to environment, and did not doubt but that this colour adaptation was for the purpose of protection, the eye producing by reflex action the change in the pigment cells. Rose HaIG ThOMAS.

\section{STELLAR PARALLAX.'}

$\mathrm{T}$ HE Delegates of the University Press have recently published the results of Prof. Pritchard's systematic investigations into the parallax of those stars of the second magnitude whose North declination permits the inquiry to be made with facility and advantage in these latitudes. Our first feeling on glancing over the contents of this brochure must be one of hearty congratulation to the distinguished professor that he has been permitted to see the full outcome of a protracted inquiry, conducted at a period in his life when a less energetic astronomer would have felt himself justified in withdrawing from active participation in scientific research.

I "Researches in Stellar Parallax by the aid of Photography." By Charles Pritchard, D.D., F.R.S., Savilian Professor of Astronomy in Oxford.

NO. 1200, VOL. 46]
Prof. Pritchard might well have been content to rest on the laurels he had won, and to have staked his reputation upon that career of acknowledged utility which has marked his direction of the Oxford University Observatory.

Immediately on the completion of the photometrical examination of Argelander's Uranometria, and with a zeal that admitted of no delay, Professor Pritchard busied himself with this inquiry into the parallax of stars of the second magnitude. But if the inquiry was undertaken with eagerness, and pursued with ardour and resolution, it was not characterized by hurry, or its success imperilled by incompleteness. Confident himself that photographic methods possessed the requisite accuracy to make the research successful and trustworthy, the Savilian Professor set to work to establish the reliable character of measurements made on sensitized films, and not till that confidence was demonstrated did he embark upon the larger work now under notice. These preliminary inquiries have been published in a series of papers in the proceedings of the Royal and Royal Astronomical Societies, and the confidence gradually acquired by enlarged experience induced him to proceed with the determination of the parallax of $6 \mathrm{r}$ Cygni, the results of which are published in detail in the third fasciculus of the Annals of the University Observatory. In this case he selected four stars in the immediate neighbourhood of the principal star, and sought the difference of parallax between each of the components and of the four stars of comparison. This long research may be regarded by some as a work of supererogation, inasmuch as the labours of Bessel and that of many later astronomers have satisfactorily settled the parallax of this star within very approximate limits. But if we properly understand the motives of Prof. Pritchard, his intention was not so much to seek anew the parallax of that system, as to discover with what degree of accuracy the method of photography, hither to unapplied in this direction, represented the work of others made directly in the field of the telescope. Nor was this his only view. By selecting four stars in the immediate neighbourhood of 6r Cygni and seeking the difference of parallax between these stars of comparison and each of the components of the system, he instituted a very severe inquiry as to the trustworthiness of that method, which he had imagined as capable of dealing with the delicate question of stellar parallax. The severity of the test consists in deducing the same value of the parallax (eight in all) from each set of measures, and as a matter of fact the accordance, inter se between these several determinations is as close as could have been anticipated, and likewise in satisfactory unison with the work of other astronomers.

The completeness of this inquiry and the publication of it in detail have had two happy results. In the first place, Prof. Pritchard has, in the present instance, been able to confine the printing within very narrow limits, so narrow, indeed, as possibly not to have done himself justice. The details of his process, the mutual agreement of his measures, and his method of discussion having all been fully set out in his previous work, he has not felt himself obliged to enter into these minute particulars, but has contented himself with presenting the results. This method of arrangement, no doubt suggested in the first place by economical motives, has afforded opportunity for adding a very interesting history of the processes and results that have hitherto been followed with more or less success by others, and also the exhibition in a concise form of the different values of the more trustworthy determinations, derived by previous observers. The second advantage, immediately arising from the earlier investigations, is, that an examination of those results has shown that no increase of accuracy (commensurate with the increased labour at 